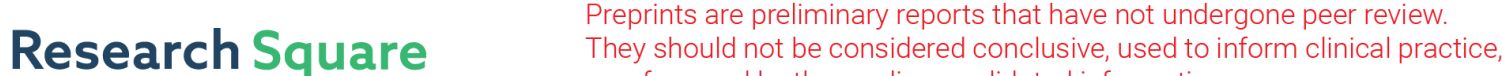 or referenced by the media as validated information. \\ Experimental Investigation of the Vortex Flow around an Axisymmetric Body with the Five-Hole Probe and Hot Wire Probe
}

amir farajollahi ( $\square$ a.farajollahi@sharif.edu )

Sharif University of Technology

Mojtaba Dehghan Manshadi

Malek-Ashtar University of Technology

Kazem Hejranfar

Sharif University of Technology

Original Article

Keywords: Axisymmetric body, Hot Wire Probe, Vortical Flow, Vortex Generator, Five Hole Probe

Posted Date: May 20th, 2020

DOI: https://doi.org/10.21203/rs.3.rs-29492/v1

License: (c) (i) This work is licensed under a Creative Commons Attribution 4.0 International License.

Read Full License 


\title{
Experimental Investigation of the Vortex Flow around an AxisymmetricBody with the Five-Hole Probe and Hot Wire Probe
}

\author{
Amir Hamzeh Farajollahi ${ }^{\mathrm{a}^{*}}$, Mojtaba Dehghan Manshadi ${ }^{\mathrm{b}}$, Kazem Hejranfar $^{\mathrm{c}}$ \\ 1- Assistant Prof., Mech. Eng., Imam Ali University, Kargar Ave, Tehran, Iran, PO Box: 1317893471, Tel.: +98 (21) 61048448 , \\ E-mail: a.farajollahi@sharif.edu \\ 2- Associate Prof., Mech. Eng., MalekAshtar University of Technology, Ferdosi Street, ShahinShahr, Esfahan, Iran, PO Box: \\ 83145-115, Tel.: +98 (31) 45227135, E-mail: mdmanshadi@mut-es.ac.ir \\ 3- Prof., Aero. Eng., Sharif University of Technology, Azadi Ave, Tehran, Iran, PO Box: 11365-11155, Tel: +98 (21) 66164603, \\ E-mail: k.hejranfar@sharif.edu
}

\begin{abstract}
Anaxisymmetric body experiences the vertical flow around itself at incidence angle. If the adverse pressure gradient is significant, the boundary layers separated and a vortex is formed. The flow over a submarine at AOA (angle of attack) has specified separation of boundary layer and large vortex structures around the body. This flow influences body drag, acoustic and maneuverability. A propermethod to decrease and control the impacts of this separated flowis to use vortex generator. The mainobjective of the present study is to investigate the flow field around a Suboff model with applying the vortex generator by using the hot wire and five-hole probe in $0^{\circ} \leq \alpha \leq 20^{\circ}$ angles of attack. The novelty of present study is application of two experimental method, (hot wire probe and five-hole probe) which can help to precisely study the structure of three-dimensional vortical flow field, the boundary layer velocity profiles and probability of the separation on the model with and without existence of vortex generator. The results indicate that vortex generators significantly decrease cross-flow separation, the size of vortices and the vortical flow.
\end{abstract}

Keywords:Axisymmetric body, Hot Wire Probe, Vortical Flow, Vortex Generator, Five Hole Probe 


\section{Introduction}

When separation occurs, the flow in the boundary layer is retarded to a point where it can no longer counteract the pressure gradient and separates from the surface. This results show adverse flow and thickening of the boundary layer downstream of the separation point. If the boundary layer flow remains attached, only a relatively small drag due to the skin friction will remain. Commonly employed methods for flow control today provide favorabletool to augment the performance of aerodynamic systems when the boundary layer is separated, or at least close to separated state (Velte 2009).

However, implementing an effective control requires to better understand the vortex and wake behavior in the close to the body and thus to better understand the relationship between the strength of vortices and the drag forces. It depends on the strength, the size and the path of the vortices in the vortical region as well as on the speed they are moving away from the body. Some theoretical approaches (Collins and Keswani 2004) have been developed taking into account different simplified kinematic motions in order to better understand the flow behavior.

The aft wake of the blunt body like (submarine) is composed of 3Dvortex structures with different flow characteristicthat is given depending mainly on the Reynolds number as the geometry (Xueying et al., 2003, Pantelatos and Mathioulakis, 2004). They have a reciprocating interaction with the near wake flow supplying the vortex street generation and being conditioned by the initial generated vortices. Turning maneuvers of blunt body result in flow separation that generates large hydrodynamic forces and moments. The vortex generators as a flow control device can be used to control this cross-flow separation on submarines. The role of the vortex formed by a vortex generator is to provide a way whereby fluid outside the boundary layer flow with higher energy can swirl with the body surface, low-velocity fluid in order to re-energize the boundary layer and delay or prevent the flow separation (Manshadi et al, 2015, 2017).

The flow visualization techniques have an important role in analyzing of the flow structures over the body. Method of the oil flow visualization is a useful technique for identifying of the skin-friction line on the body surfaces (Saidinezhad et al, 2014, Ashok and Smits, 2013, Kumar et al., 2012,Liu et al. (2011), Etebari et al., 2008, Gregory et al. 2007, Mackay 2003, Hosder and Simpson 2001).

Saiedinezhad and colleagues (2012) performed a set of experiments of visualization on the model of the Suboff submarine at different angles of attack in a subsonic wind tunnel. To study the physics of visualization experiments, 
they performed them by oil and pigmentation. Test results of visualization indicate the location of the secondary flow separation on the model, also the test results of visualization, and the flow separation line at the stern gets more evenly. In addition, to see how the formation and the development of cross vortex on the model tests of visualization are carried out by the smoke. Results of visualization indicated visible smoke at the stern or bottom of the transverse vortexes gets bigger and more developed than its location.

DehghanManshadi et al. (2017) performed a set of experiments of visualization on the model of the bare hull Suboff submarine by the oil and pigmentation at different angles of attack in a subsonic wind tunnel and also the numerical simulation on the model with the OpenFOAM software. They used three sizes of the vortex generators (small, mid., large) on the surface of the bare hull model. It has been shown that the mid. vortex generators placed along the submarine center line from bow to stern do indeed significantly reduce the cross-flow separation on the submarine. Also, the drag force was reduced and the secondary separation was eliminated with the vortex generators.

Review of the previous studies indicates that the five-hole probe was used to study the vortex fields. Maseland et al. (1992) numerically and experimentally studied the flow around a double delta wing.In order to validate their numerical code developed to analyze the flow field to double delta wing, a five-hole probe was used at the apex angle of 45 degrees. By this method, vortical flows induced on the wingswere measuredand the results were compared with each other. Blomhoff (2012) put a model wind turbine into the wind tunnel in order to observe the changes in the sequence of the wind turbine, and by a five-hole probe measured wake of the wind turbine at different section and also measured the various parameters.

The main aim of the present work is the study experimentally the effect of the vortex generators on the flow field characteristic of a Suboff model. The present work is devoted to determine the effect of vortex generators on the flow structures over and around a submarine model in an angle of attack by the hot wire anemometer and five-hole probe at Reynolds number of $1 \times 10^{6}$. In this study, two experimental methods are used and the effect of the vortex generators on the standard submarine model was studied and discussed.

\section{Experimental setup}

\subsection{Wind Tunnel for Hot Wire Probe Measurements}

The experiments in the present work are conducted in a closed loop subsonic wind tunnel with a test section size of $370 \times 280 \times 1200 \mathrm{~mm}$. The axial fan of the tunnel provides air flow with maximum speed of about $30 \mathrm{~m} / \mathrm{s}$ and 
turbulence intensity level of $0.25 \%$ in the test section. The test section has 45 degree corner fillets which enlarge the cross-sectional area gradually in downstream direction to maintain a constant static pressure along the test section, therefore decreasing the buoyancy effects.

The boundary layer velocity profiles in the plane of symmetry on the leeward side $\left(\varphi=180^{\circ}\right)$ of the submarine were measured by using a single probe of hot wire anemometer (Fig. 1). The single probe with $0.5 \mathrm{~mm}$ tungsten wire is mounted on a three-dimensional traverse system with an accuracy of $0.01 \mathrm{~mm}$. To measure the boundary layer accurately, the probe moves in a line normal to the model surface logarithmically controlled by computer software and the data are acquired during 5 second for each location. The CTA (constant temperature anemometer) has a temperature corrective probe that is placed in the flow and applies the effect of temperature variation during air flow measurement. The results were obtained for model with both model shapes (with the vortex generators and without the vortex generators) for $\mathrm{Re}=1 \times 10^{6}$ at three pitch angles $\alpha=0,5$ and $10^{\circ}$ with the trip strip on the nose. The measuring parameters and their uncertainty are listed in table 1.

Table 1.The relation and uncertainty of the all parameters.

\begin{tabular}{lll}
\hline Parameter & Relation & Relative uncertainty (\%) \\
\hline Free stream velocity $(\mathrm{m} / \mathrm{s})$ & $V_{\infty}$ & $\mathbf{1 . 9}$ \\
Reynolds number & $\mathrm{Re}$ & $\mathbf{2}$ \\
Mean velocity $(\mathrm{m} / \mathrm{s})$ & $\mathrm{U}$ & $\mathbf{3}$
\end{tabular}

\subsection{Wind Tunnel for Five-Hole Probe Measurements}

All experimentsin this study have beenperformedinanopen circuit wind tunnel at Yazd University (Fig.2).The wind tunnel has a maximum fan powerof $32 \mathrm{Kw}$ and maximumvelocityof $30 \mathrm{~m} / \mathrm{s}$ inside the testroom. The wind tunnel test chamber has a cross-sectionof $457 \times 457 \mathrm{~mm}^{2}$ and length of $1200 \mathrm{~mm}^{2}$ and has four transparent Plexiglas window glass at dimensionsof $267 \times 572 \mathrm{~mm}$.Inordertoavoid the interference of boundary layers bysidewalls, the corners of 45 degreeangle were mounted between twowalls. The size of the cornersalong the test room gets small and it causes the enlargement of the cross-section and destroys partly their floating longitudinal effect along the test room.Coefficient of obstructions or blockage ratio in models plus its kickstand in the wind tunnel test chamber is equal to 
4.9\%percent.That's less than the standard value (5\%) and therefore is reliable.Allof this researchtests is at velocityof $16 \mathrm{~m} / \mathrm{s}$. Turbulenceintensityin the test chamber is about 0.25 percent.

In order to use the five-hole probe,itisneededtomeasurethefive pressure channels.For this reason, a 15channelpressure converterdeviceis used. This pressure sensor device is capable ofmeasuringthe maximum differential pressure $\pm 1270 \mathrm{~Pa}$ at accuracy of $\pm 3 \mathrm{~Pa}$.Measured Data are entered directly through a 12-bit analog to digital voltage converter card into the computer and the necessary software and computing has been done on them. According to the five-hole probe relations, measuring the relative uncertainty for pressure and average velocity are obtained of 0.16 and 8.7 , respectively.

\subsubsection{Introducing the five-hole probe and its calibration}

Multi-hole probe is one of the sonic laboratory equipment to determine the factors of flow. The use of multi-hole probes began from the second decade of the 20th century and continues today. The probes are used not only in the laboratory but also are used in the aircrafts and helicopters. Multi-hole probes are used to determine the components of flow velocity and total pressure. The probe can be used to study three dimensional vortical fields. According to the five-hole probe advantages compared to other measurement methods, the study of a five-hole probe is applied to evaluate the three dimensional vortical fields.

The probe isbasedonthe operating principle ofthe pressure distribution on the surface in front of a circular object that is placed in fluid flow.Pressure distribution on the surface has a maximum value at the point of stagnation flow and pressure on the surface of the model at thedownstream reduced. Maximum pressure for round objects is the total pressureof $\mathrm{p}_{0}$ that is sum of static pressure $\left(\mathrm{p}_{\infty}\right)$ and dynamic pressure $(\mathrm{q})$ away from the body and the lowest pressure is in the region where the slope body is parallel to the direction of flow.According to this point it canbemeasuredbydifferent pressure points on the surface of a circular object, the angle of the flow in respect to the object can be determined.The probe is intended for experimental study of five metal pipes with outer diameter1mm.A schematic of the probe is shown in the Fig.3. These tubesare cut at an angle of 45 degrees and placed side by side.

A five-hole probe must be calibrated before using.Calibration means that the relationship between measured

pressure and flow angles by the probeisobtainedin the measurement location. Theserelationsarederived for 
dimensionless coefficientsthatcanbe usedaccording to the flowangle.After the calibration process, measuringfive pressures by a five-hole probe should be conducted to determine the flow angle. Calibration of the airflow is done by an open circuit wind tunnel. To gain a uniform flow a honeycomb mesh is used in the wind tunnel.In this study to calibrate five-hole probe is the following: 1) the mechanism of the probe angle 2) direct flow generated in the wind tunnel test section, 3)pressuremeasuring system,4) Software for obtainingdata.Fig. (4) shows the five-hole probe calibration equipment. Fig. (4a) indicates five-hole probe, (4b) 15-channel pressure transducer) and (4c) mechanisms of the probe angle.

The probe pressure values are takenand by using the static pressure and total pressure getting from pitot probe the dimensionless numbersare obtained.This processis repeatedfor different yaw and pitch angles.The calibration curve of the probe is obtained based on four parameters of yaw and pitch and dimensionless coefficients. Since pitch and yaw angles can be attributed to the read pressures by different holes, it is necessary to determine the condition of pressure dimensionless coefficients. There are several ways to define the pressure dimensionless coefficients.In this study, the relationship proposed by Treaster and Yocum (1979) is used.Dimensionless pressure coefficients are defined for equation (1).

$$
\begin{gathered}
\mathrm{C}_{\mathrm{p}_{\alpha}}=\frac{\mathrm{p}_{1}-\mathrm{p}_{3}}{\mathrm{p}_{5}-\overline{\mathrm{p}}} \\
\mathrm{C}_{\mathrm{p}_{\beta}}=\frac{\mathrm{p}_{2}-\mathrm{p}_{4}}{\mathrm{p}_{5}-\overline{\mathrm{p}}} \\
\mathrm{C}_{\mathrm{p}_{\text {total }}}=\frac{\mathrm{p}_{5}-\mathrm{p}_{\text {total }}}{\mathrm{p}_{5}-\overline{\mathrm{p}}} \\
\mathrm{C}_{\mathrm{p}_{\text {satac }}}=\frac{\overline{\mathrm{p}}-\mathrm{p}_{\text {static }}}{\mathrm{p}_{5}-\overline{\mathrm{p}}} \\
\overline{\mathrm{p}}=\frac{\left(\mathrm{p}_{1}+\mathrm{p}_{2}+\mathrm{p}_{3}+\mathrm{p}_{4}\right)}{4}
\end{gathered}
$$


In these relations the parameters of $\mathrm{C}_{\mathrm{Pa}}$ and $\mathrm{C}_{\mathrm{P} \beta}$ are dimensionless pressure coefficient for flow angle vertically (pitch) and horizontally (yaw) respectively that through those probe angles in the calibration phase and flow angles in step recovery flow parameters are associated to five-hole pressure probe. Also $\mathrm{C}_{\text {Ptotal }}$ parametersand $\mathrm{C}_{\text {staticare }}$ thetotal and staticdimensionless pressure coefficients created by these coefficients of total and static pressure and can be achieved at any point mentioned using two pressures mentioned and by using equation (2) the velocity is gained at each point.

$$
|\mathrm{V}|=\sqrt{\frac{2\left(\mathrm{P}_{\text {tot }}-\mathrm{P}_{\text {stat }}\right)}{\rho}}
$$

Generally, five-hole probe calibration procedure is so that first five-hole probe within an open circuit wind tunnel is installed on the angle device andprobepressure holes are connected to electronic transducer.Then putting the probe indifferent angularpositionsofthe pressure in each measurement and using relationships described in (1) the pressuresare converted at any pointinto dimensionless pressure coefficients.As noted above, after calibrating the process and obtainingdimensionlesscoefficientsare plotted on a curve as well. The resulting curve is known as a calibration curve.In Fig.5 calibration diagram obtained from five-hole probe calibration curve is shown at the inlet flow velocity $16 \mathrm{~m} / \mathrm{s}$.

\subsubsection{Testing process}

The general test trend is so that after verifying five-hole probe, the probe shallbe placedin a wind tunneland the flow passing through the model by shifting the five-hole probe through the points in a perpendicular plate to the flow, the pressure values for each hole are read andrecorded by a pressure transducer.

Tocheckthe accuracyof measurementsperformancebya present experimental studythe reproducibility of results and values of uncertainty was carried out. In following to investigate each of thesepartswillbe discussed.

\section{A) Reviewof Results Repeatability}

In experimental studiesthe measurementofvalues usually are different at the each iteration.But each timemeasurementresults will be as reliableas possible, difference is less than to each other.It has been installed 
inside the tunnel while thedataforaline in the flow field around the modelweremeasuredtwice, at two differenttimes.As it canbe seenin both testsmeasuredpressuredifferencesare notsignificantand are much closer to each other.Sowecanclaim that they are repeatable experiments.To repeat calibration curve, three tests were conducted and the results were compared for all three tests. The resultsfor $\alpha=21.6$ in all three tests are shown in the Fig.6.As canbeseen,there is very little difference between the results and theconclusion that they are repeatable experiments conducted by researchers with good accuracy.

\section{B) Determinationof Uncertaintyin Measurement Parameters}

The measuring process ofa physical quantity is always contaminated to some error.Lack of knowledge about the size and sign of the error in the measurement is called by uncertainty.Estimation of uncertainty, description and evaluation of themeasurementerroris a statisticaland results of measurementonly to complete when a quantity of uncertainty is described.

\section{B.1) uncertainty of pressure coefficients $c_{p_{\alpha}}, c_{p_{\beta}}$}

According to the definition ofdimensionlesscoefficientsof pressure to five-hole probe in equation (1), it canbe calculated using equation (3) level of uncertaintyachieved for each of thequantities.For example, the uncertainty associated the quantityzisas a function of two independent quantitiesx and y definedasfollows:

$$
u_{z}=\sqrt{\left(\frac{\partial z}{\partial x} u_{x}\right)^{2}+\left(\frac{\partial z}{\partial y} u_{y}\right)^{2}}
$$

Pressure uncertainty of averagesideholes inprobe due to the uncertainty of pressure $\operatorname{sensors}\left(u_{p}=3 p a\right)$ isdefinedasfollows:

$$
u_{\bar{p}}=\sqrt{\frac{1}{4} \times 4 u_{p}^{2}}=u_{p}=3 p a
$$

Uncertainty of pressure coefficients: 


$$
u_{C_{p u}}=\sqrt{2 \times\left(\frac{1}{\left(p_{5}-\bar{p}\right)} u_{p}\right)^{2}+\left(\frac{p_{3}-p_{1}}{\left(p_{5}-\bar{p}\right)} u_{p}\right)^{2}+\left(\frac{p_{3}-p_{1}}{\left(p_{5}-\bar{p}\right)^{2}} u_{\bar{p}}\right)^{2}}
$$

Given the amount of available data the placement of $30 \mathrm{~Pa}$ for $\left(p_{3}-p_{1}\right)$ and 90 Pascal to $\left(p_{5}-\bar{p}\right)$ and placement of uncertainties of pressure sensors $\left(u_{p}=3 p a\right)$ value of the uncertainty for pressure coefficient $\left(C_{p \alpha}\right)$ is approximately equal to 0.015 . The pressure coefficient $\left(C_{p \beta}\right)$ applies the same relationship.Only insteadof $\left(p_{3}-p_{1}\right)$, $\left(p_{4}-p_{2}\right)$ is used by 70 Pascal.Substituting the amount of uncertainty is equal to 0.036 .

\section{B-2) Uncertainties of the angles $\alpha$ and $\beta$}

The amount of velocity isobtained at every point of equation (2). The uncertainty velocity by using equation (3) isobtainedfrom the followingequation:

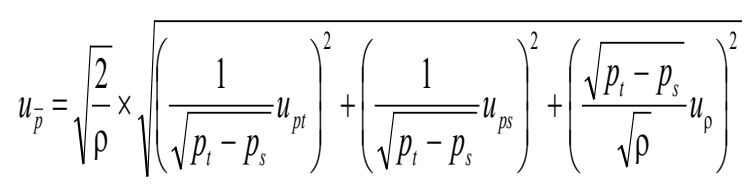

Substituting $17 \mathrm{~Pa}$ the uncertainty of total pressure and $18 \mathrm{~Pa}$ for to uncertainty of the static pressure and the amount of $2 \times 10^{-5} \mathrm{Kg}$ per cubic meter for the uncertainty density and maximum differential pressure of $256 \mathrm{~Pa}$ for total and static pressure, the uncertainty of velocity is 1.47 meters per second and it'swill be relatively equal to 0.087 .

\section{Results and Discussion}

\subsection{Experimental Results (five-hole probe)}

The streamlines patterns and vorticity contours for the model without the vortex generators for the plane YZ for $\alpha=20^{\circ}$ is shown in Fig.8. At $X / L=0.5$, the streamline patterns show the separation of flow field from the suction side and the two counter vortices be larger at the downstream of the body. Also, core of the vortex moves away from the body surface result inform the circumferential pressure gradient to interact with the vortex core and it's diffuses and becomes larger. This is seen at $X / L=0.7$. 
Fig.9 shows the vorticity contours and the streamlines patterns at different streamwise locations at $\alpha=20^{\circ}$. The vortices created around the body may affect the hydrodynamic forces and performance of the submarine model. As angle of attack increases, the cross-flow velocity causes the flow separation on the leeward side of the model and allows the boundary layer flow to be moved away from the body surface. This is a natural 3-D flow separation due to the angle of attack in which primary and secondary vortexes create with different characteristics.

Fig. 10 shows the vorticity contours and streamlines patterns for the models (with and without the vortex generators) at different streamwise locations at $\alpha=20^{\circ}$. Fig. 11 shows the compare of the speed ratios for the models (with and without the vortex generators) at $X / L=1.1$; and Fig. 12 shows the vortex core for the both models (with/without the vortex generators) at $\alpha=20^{\circ}$. The results show that the model without the vortex generators has a stronger vortex than the model with the vortex generators. In fact, increase in the vorticity strength and the drag force for the model without the vortex generators is because the vortices created in each row are damped by the next row and thus they become ineffective and result in preventing the boundary layer separation. The model with the vortex generators has a smaller vortexes and separation zone and also the vortex core has a smaller distance from the surface of body and has a smaller reduction of speed ratio with respect to the model without the vortex generators. It shows that the submarine with vortex generators is more controlled the separation of the boundary layer compared to the model without the vortex generators, and for the model with the vortex generators the flow is attached to the surface. Due to the cross flow interaction, the vortex cores expand out at $X / L=0.7$.

\subsection{Experimental Results (hot wire probe)}

In order to investigate the effect of the vortex generators around the submarine model, in addition to the five-hole probe, the hot wire anemometry is performed. Using the hot wire probe, the distribution of the velocity profile of boundary layer, turbulence intensity and instantaneous velocity can be obtained at different angles of attack and also, the effects of using the vortex generators on the flow structure can be studied.

In this section, the velocity profiles of boundary layer on the symmetry plane of the submarine nose $\left(\varphi=180^{\circ}\right)$ are studied for $\operatorname{Re}=10^{6}$ at two angels of attack $\alpha=0$ and $10^{\circ}$. Moreover, the boundary layer profile in the location $\mathrm{X} / \mathrm{L}=$ 0.9 is measured to compare with Huang and Liu result. Fig. 13 shows the boundary layer velocity profile in location 
$\mathrm{X} / \mathrm{L}=0.9$ on the leeward symmetry plane $\left(\varphi=180^{\circ}\right)$ for suboff model at zero pitch angle and $\mathrm{Re}=10^{6}$. The result of Huang and Liu is also shown in this figure. The velocity profile of the boundary layer $\left(U / U_{e}\right)$ depicts in nondimensional distance from the surface $\left(\mathrm{Y}-\mathrm{R}_{0} / \mathrm{R}_{\mathrm{Max}}\right)$. Comparing the present results with the experiments shows that the trend of the velocity profile of the boundary layer are very well predicted by present work, but the differences are seen in range of distance $0.5 \leq\left(\mathrm{Y}-\mathrm{R}_{0} / \mathrm{R}_{\mathrm{Max}}\right)$. In the present work, $\mathrm{U}_{\mathrm{e}}$ is the velocity at the edge of the boundary layer in position $\mathrm{X} / \mathrm{L}=0.9$ but Huang and Liu used the velocity of the flow outside of the boundary layer in position $\mathrm{X} / \mathrm{L}=0.75$ that its value is unknown. This may be the reason of the discrepancies between the results.

Fig. 14 shows the contours of the flow at different streamwise locations measured by using hot wire probe for $\alpha=10$ degree indicate stream-wise vortices on the leeward side for two models (without V.G. (left) and with V.G. (right)). This Figure illustrates as moving along the model length from the nose to stern, the vortical flow grows in size. Also, this figure shows the model with the vortex generators has small vortical region and thus a small separation zone. It means the model with the vortex generators is more effective for controlling the boundary layer separation and prevents the flow separation from the hull compared to the model without the vortex generators.

Fig. 15 shows the variation curves of the axial wake against the circumferential angle with and without the vortex generators at $\mathrm{X} / \mathrm{L}=1.1$. Fig. 15 shows that the vortex generators reduce the variation extent of the axial wake velocity. It suggests that the vortex generators can weaken the horseshoe vortex and improve the uniformity of the wake at the propeller disc, which is beneficial to the working propeller.

Fig. 16 shows the boundary layer velocity profiles in four locations $\mathrm{x} / \mathrm{L}=0.55,0.65$ and 0.75 along the body surface of two models with the vortex generator and without the vortex generators at angle of attack equal to 10 degree $\left(\alpha=10^{\circ}\right)$ and for Reynolds number $1 \times 10^{6}$. The streamwise component of the velocity (U) becomes nondimensionalized with the magnitude of the velocity at the boundary layer edge $\left(\mathrm{U}_{\mathrm{e}}\right)$. The vortex generators are placed along the top and bottom centerlines of the submarine from nose to stern in order to energize the cross-flow of the boundary layer and prevent the cross-flow separation around the model. The vortex generators create the small vorticities in the flow field and prevent growing of the vortical flow and the flow separation from the hull. In general, the role of the vortex created by a vortex generator is to provide a mechanism whereby higher energy fluid outside the boundary layer can swirl with the near surface low velocity fluid in order to re-energize the boundary layer and delay or prevent this separation. 
Fig. 17 indicates a graph instantaneous velocity per time at different sections $(\mathrm{X} / \mathrm{L}=0.55,0.75)$ for two different models. According to the diagrams it has been shown that the instantaneous velocity of the model without the vortex generators increases. This increase is due to growth of flow vortices and flow separation because of horseshoe vortex that created by presence of sail on the model. It also is seen that the use of the vortex generator helps to control the vortical flow and prevent increasing the moment speed. It means that using of the vortex generators can decreases the horseshoe vortex and control the flow.

In Fig. 18, the diagram has shown the turbulence intensity for the vertical distance of surface model. As it is clear, distancing from the surface first the turbulence intensity increased then decreased to get the free stream turbulence intensity. In addition, according to the figure it has observed that the vortex generators reduce the turbulence intensity around the model. In fact, as mentioned earlier, the vortex generators, controlling the boundary layer flow and prevent the vortex flow separation (which in this area it has shown high turbulence intensity). In fact, at the stern of the model is the location of the propeller, and the vortex generators by controlling the flow separation reduce noise and voricity which in turn leads to increased efficiency and reduced noise of the propeller and drag force.

\section{Conclusion}

In the present study, to investigate the physics of the flow field structures around the submarine model is investigated experimentally with two technique, five-hole probe and hot wire probe. The results of the five-hole probe show patterns of the vortical flowaround the model. The results of the hot wire probe show the velocity profile of boundary layer, turbulence intensity and instantaneous velocity.The major conclusions are summarized as follows:

- At the angles of attack, the vortex generators reduces the vortical flow region and the separation zone. Note that the vortex generators can energize the boundary layer prevent the growth and strength of the vortices around the body. The drag force is also decreased by using the vortex generators.

- The study shows the secondary separation lineeliminatesfor the model with vortex generator. Also,the vortex generators cause the flow separation region over the bodyto be reduced. 
- The study indicates that the vortex generators reduce the size and strength of the vortical flow around the model and both the experimental results verify this behavior.

- The study indicates that thebody with vortex generator has a smaller reduction speed ratio and a smaller vortex core.

- Indications are that the model with the vortex generators is more effective for controlling the boundary layer separation compared to the model without the vortex generators and this effect is more pronounced at high angles of attack. 


\section{Declaration}

Availability of data and materials: Not applicable.

- Competing interests: Not applicable.

- Funding: Not applicable.

\section{- Authors' contributions:}

Amir Hamzeh Farajollahi: Designed and performed experiments, analyzed data and co-wrote the paper.

Mojtaba Dehghan Manshadi: Performed experiments.

Kazem Hejranfar: Designed experiments and co-wrote the paper.

\section{- Acknowledgements:}

I thank the following individuals for their expertise and assistance throughout all aspects of our study and for their help in writing the manuscript.(Ali saidinezhad and Ali Akbar Dehghan). 


\section{References}

Velte, C.M., Velte, (2009) Characterization of Vortex Generator Induced Flow, DCAMM Special Repport No. S118, MEK-PHD 2009-07/ISBN 978-87-90416-37-9, Department of Mechanical Engineering, Technical University of Denmark, July, 2009.

Collins, L.R. and Keswani, A. (2004) Reynolds Number Scaling of Particle Clustering in Turbulent Aerosols, New Journal of Physics 6, 119, https://doi.org/10.1088\%2F1367-2630\%2F6\%2F1\%2F119.

Dehghan Manshadi M, Hejranfar K, Farajollahi A H. Numerical and experimental investigation ofeffect of vortex generators on flowover suboff bare hull model. Modares Mechanical Engineering. 2015; 15 (6) :81-90, URL: http://journals.modares.ac.ir/article-15-10020-en.html

Dehghan Manshadi M, Hejranfar K, Farajollahi A H. Numerical and Experimental Investigation of Hydrodynamic Behavior of a Horseshoe Vortex around sail. marine-engineering. 2017; 12 (24) :1-11,URL: http://marineeng.ir/article-1-473-en.html.

Saeidi Nezhad, A., Dehghan, A.A., and Dehghan Manshadi, M., (2014) Nose Shape Effect on the Visualized Flow Field Around an Axisymmetric Body of Revolution at Incidence, Journal of Visualization., DOI 10.1007/s12650-014-0226-1.

Xueying, D., Gang, W., Xuerui, C., Yankui, W., Peiqing, L., Zhongxiang, X., (2003) A Physical Model of Asymmetric Vortices Flow Structure in Regular State over Slender Body at High Angle of Attack. SCIENCE IN CHINA (Series E) 46 (6):561-573. doi:10.1360/02ye0164.

Pantelatos, D.K., and Mathioulakis, D.S., (2004) Experimental Flow Study over a Blunt-Nosed Axisymmetric Body at Incidence. Journal of Fluids and Structures. 19: 1103-15.

Gregory, Pa., Joubert, P.N., and Chong, MS., (2007) Measurements of Turbulent CrossFlow Separation created by a Curved Body of Revolution. Journal of Fluid Mechanics 589:353-374. doi:10.1017/S0022112007007689.

Mackay, M., (2003) Wind Tunnel Experiments with a Submarine Afterbody Model.

Hosder, S., Simpson, R.L., (2001) Unsteady Turbulent Skin Friction and Separation Location Measurements on a Maneuvering Undersea Vehicle. AIAA paper 1000.

Ashok, A., and Smits, A.J., (2013) The Turbulent Wake of a Submarine Model in Pitch and Yaw.1-16. 
Etebari, A., Atsavapranee, P., Bassler, C., and Carneal, J., (2008) Experimental Analysis of Rudder Contribution to Roll Damping,” Proc. 27th Intl. Conf. on Offshore Mechanics and Arctic Engineering, Estoril, Portugal.

Kumar, C., Manovski, P., and Giacobello, M., (2012) Particle Image Velocimetry Measurements on a Generic Submarine Hull Form.4-7.

Liu, Y., Yang, W.C., and Yang, J.M., (2011) A Visualization Study of the Near-Wall Behaviors of an Oblique Plate at Different Angles of Attack. Journal of Visualization 14:141-148. doi:10.1007/s12650-011-0086-x.

A Saeidi Nezhad, A A Dehghan, M D Manshadi, and M Kazemi Esfeh, Experimental Investigation of the Vortex Structure on a Submersible Model, Modares Mechanical Engineering, Vol. 13, pp. 98-109, 2012.(In Persian)

Manshadi, M.D., Hejranfar, K. \& Farajollahi, A.H. Effect of vortex generators on hydrodynamic behavior of an underwater axisymmetric hull at high angles of attack. $J$ Vis 20, 559-579 (2017). https://doi.org/10.1007/s12650-016-0412-4

Maseland, J., and Verhaagen, N., (1992) Experimental and Numerical Investigation of Vortex Flow over a 76/60deg Double-Delta Wing, Delft University of Technology, Faculty of Aerospace Engineering.

Blomhoff, H.P., (2012) An Experimental Investigation of Wind Turbine Wakes, in Department of Energy and Process Engineering, Norwegian University of Science and Technology, Trondheim.

Kazemi Esfeh., M., Dehghan, A. A., Dehghan Manshadi, M., (2012) Experimental Investigtion of Upstream Structures Influence on the Ventilation Performance of One-Sided Wind-Catchers, Modares Mechanical Engineering, Vol. 13, pp. 49-60.(In Persian).

Watt G, Nguyen V, Cooper K and Tanguay B., (1993) Wind tunnel investigations of submarine hydrodynamics, The development of the DREA static test rig and some results. Can Aeronaut Space J; 39: 119-26.

Treaster, A.L., and Yocum, A.M., (1979) The Calibration and Application of Five-Hole Probes, ISA Transactions, Vol. 18, No. 3.

Huang, T., Liu, H.L., Groves, N., Forlini, T., Blanton, J., and Gowing, S., (1992), “Measurements of Flows Over an Axisymmetric Body with Various Appendages in a Wind Tunnel: the DARPA SUBOFF Experimental Program", Nineteenth Symposium on Naval Hydrodynamics. Seoul, Korea. 


\section{List of Figures}

\begin{tabular}{|c|c|}
\hline 1 & Submarine model set in the open loop wind tunnel at angle of attack for oil flow visualization. \\
\hline 2 & Open loop wind tunnel for five-hole probe measurement. \\
\hline 3 & Schematic of the probe of five-hole probe \\
\hline 4 & Five-hole probe calibration equipment. \\
\hline 5 & Calibration diagram obtained from five-hole probe calibration curve. \\
\hline 6 & Repeatability test for the calibration curve $(\alpha=21.6)$ for the three tests. \\
\hline 7 & Dimensions and shape of the vane half delta-wing vortex generator. \\
\hline 8 & The comparison of vortical flow around bare hull suboff model at different section and at $\alpha=20^{\circ}$. \\
\hline 9 & $\begin{array}{l}\text { The comparison of velocity contour and vortex flow around the bare hull Suboff model at different } \\
\text { angles of attack }\left(\alpha=15 \& 20^{\circ}\right) \text { at } X / L=0.7 \text {. }\end{array}$ \\
\hline 10 & $\begin{array}{l}\text { The comparison of vortex flow around the two models (up) with V.G (down) without } V . G \text { at } \alpha=20^{\circ} \\
\text { and at } X / L=0.7 \text {. }\end{array}$ \\
\hline 11 & $\begin{array}{l}\text { The comparison of reduction speed ration for the models with/without the vortex generators at } \\
X / L=1.1\end{array}$ \\
\hline 12 & $\begin{array}{l}\text { The comparison of amount of vortex core for the models with/without the vortex generators for } \\
\text { different section at } \alpha=20^{\circ} \text {. }\end{array}$ \\
\hline 13 & $\begin{array}{l}\text { Boundary layer profiles in location } \mathrm{X} / \mathrm{L}=0.9 \text { at zero pitch angle and } \mathrm{Re}=10^{6} \text { for SUBOFF model in } \\
\text { comparison with experimental study of Huang and Liu. }\end{array}$ \\
\hline 14 & $\begin{array}{l}\text { Contours of flow around the Suboff model in four locations } x / L=0.45,0.55,0.65 \text { and } 0.75 \text { along } \\
\text { the two body surface (with and without the vortex generators) at angles of attack } 10^{\circ} \text { and } \\
\text { Reynolds number of } 1 \times 10^{6} .\end{array}$ \\
\hline 15 & Comparison of axial wake velocity with and without the vortex generators. \\
\hline 16 & $\begin{array}{l}\text { Comparison of Boundary layer profiles in locations } X / L=0.55,0.65 \text { and } 0.75 \text { at zero pitch angle and } \\
\operatorname{Re}=1 \times 10^{6} \text { for the SUBOFF model with/without the vortex generator. }\end{array}$ \\
\hline
\end{tabular}


17 Instantaneous velocity per time at two sections $X / L=0.55$ and 0.75 for two different models. Turbulent intensity at two sections $X / L=0.55$ and 0.75 at $\alpha=10^{\circ}$ and Reynolds number of $1 \times 10^{6}$ for 18 two different models. 


\section{Figures}

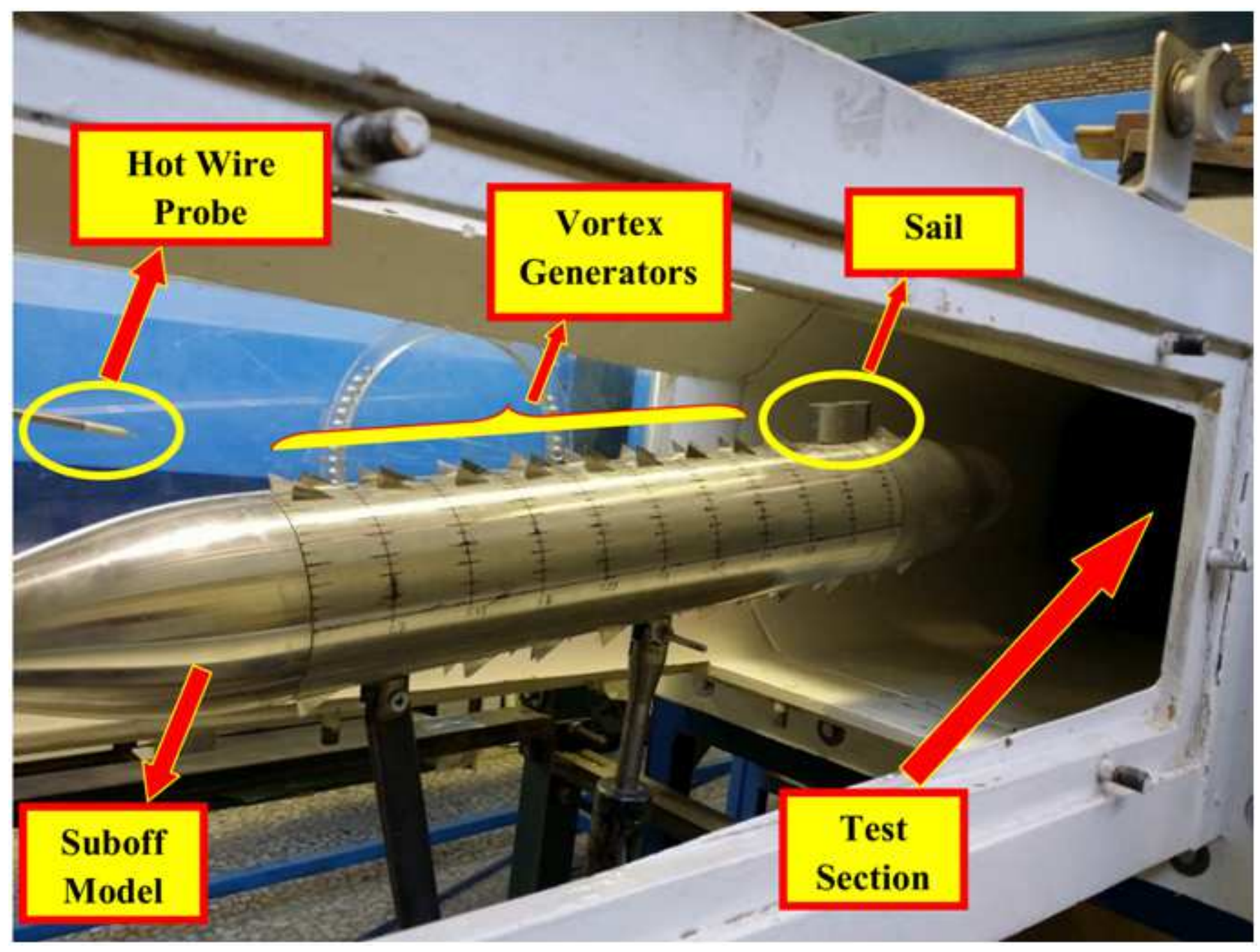

Figure 1

Submarine model set in the open loop wind tunnel at angle of attack for oil flow visualization. 


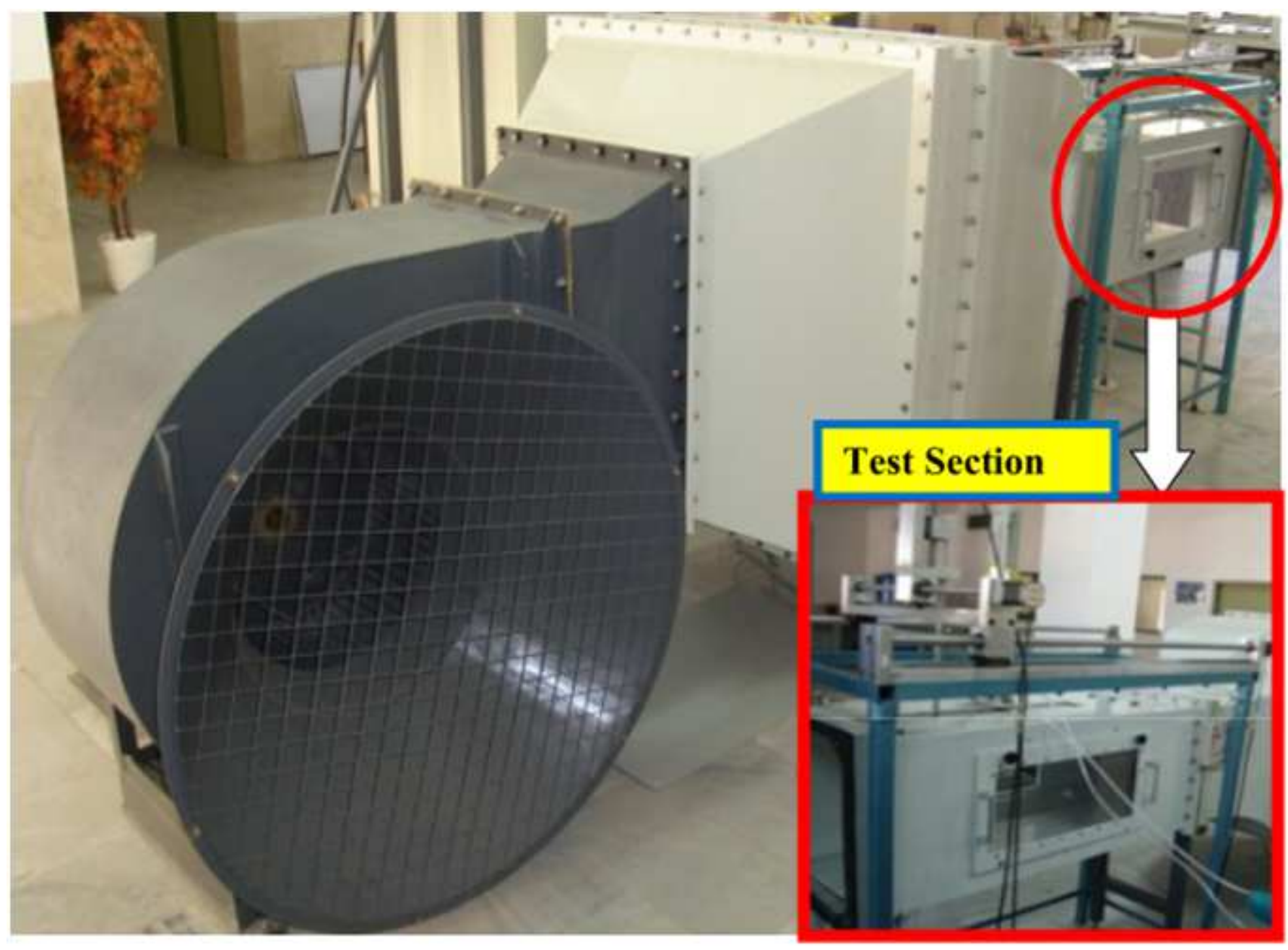

Figure 2

Open loop wind tunnel for five-hole probe measurement. 


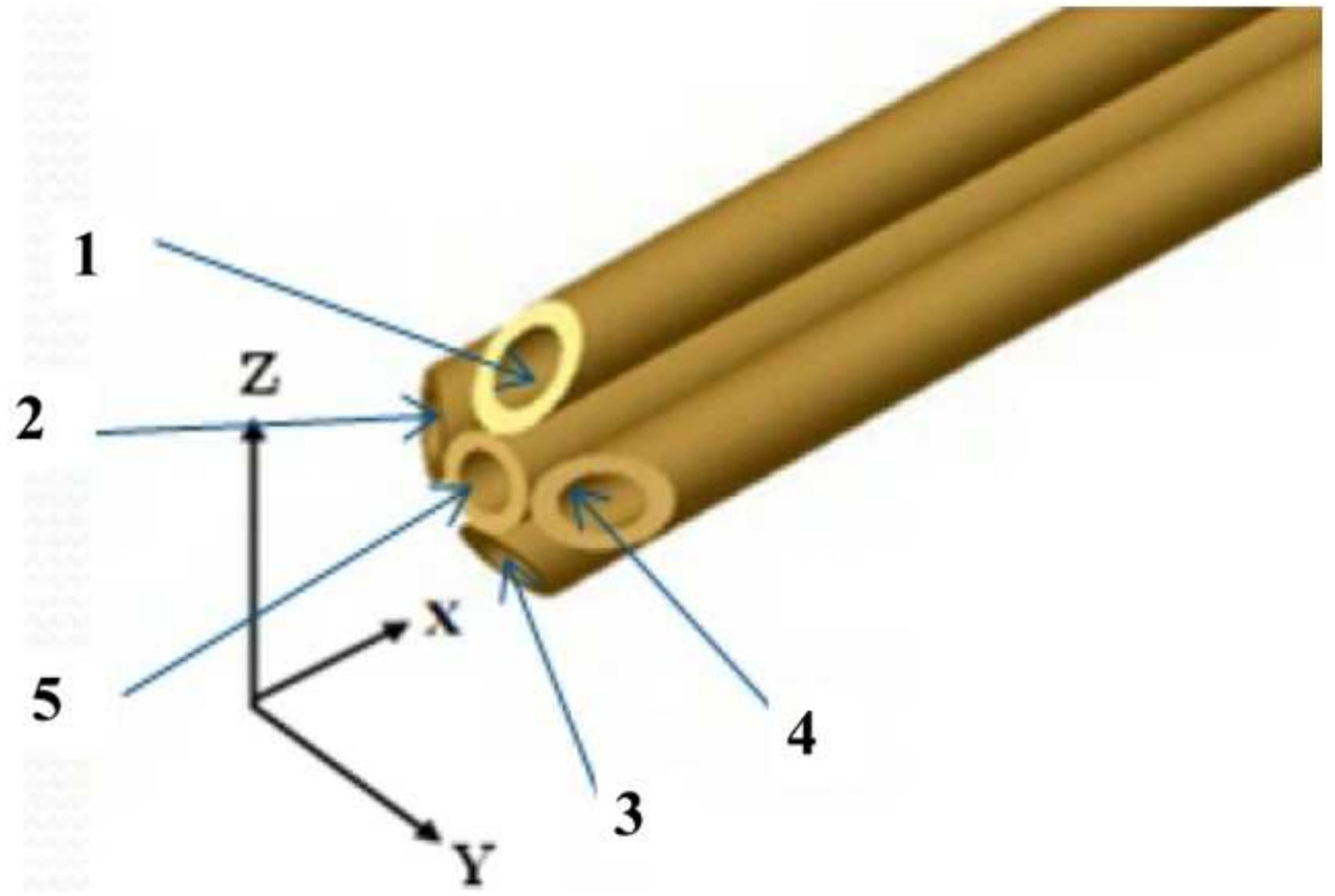

Figure 3

Schematic of the probe of five-hole probe

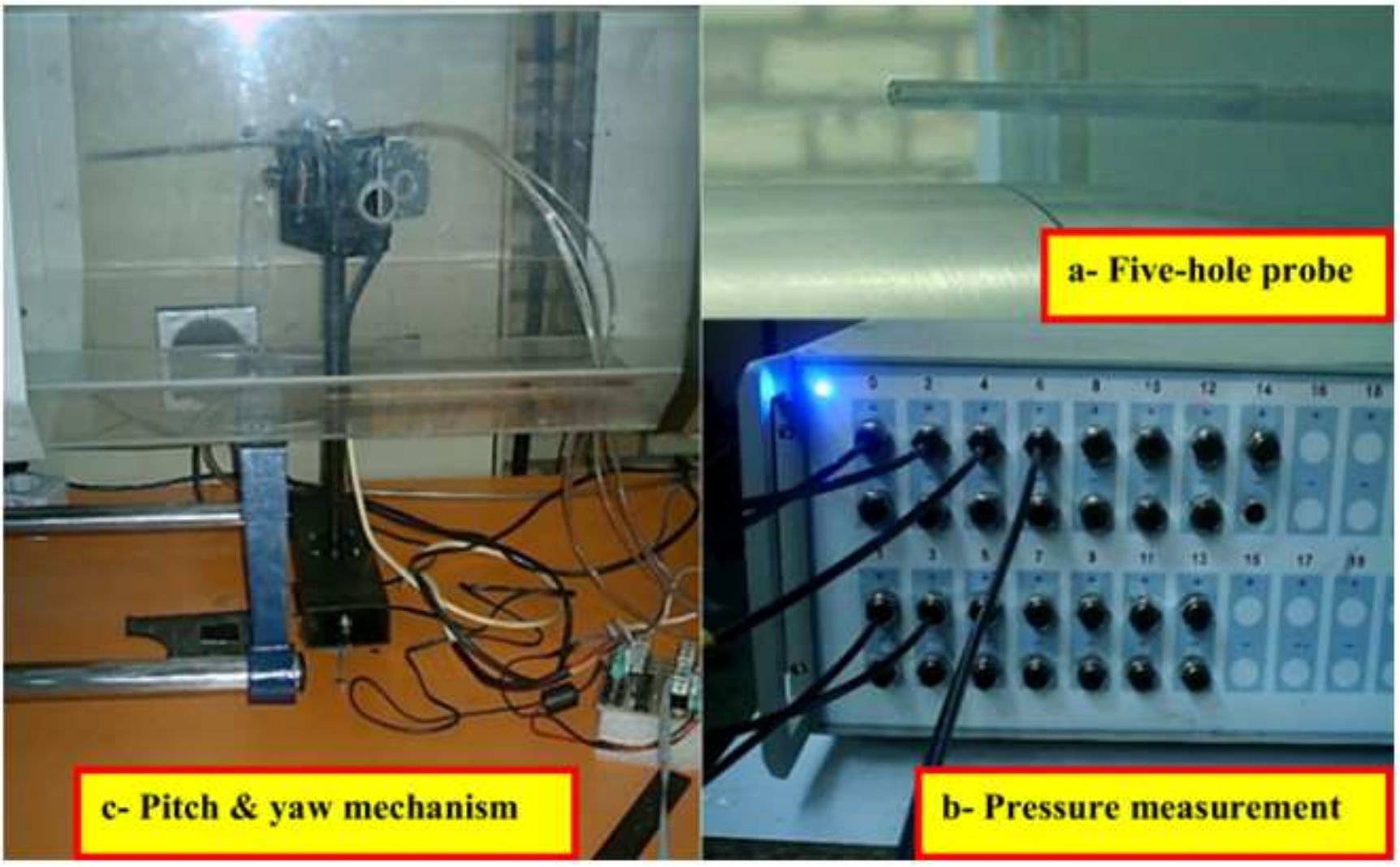


Figure 4

Five-hole probe calibration equipment.

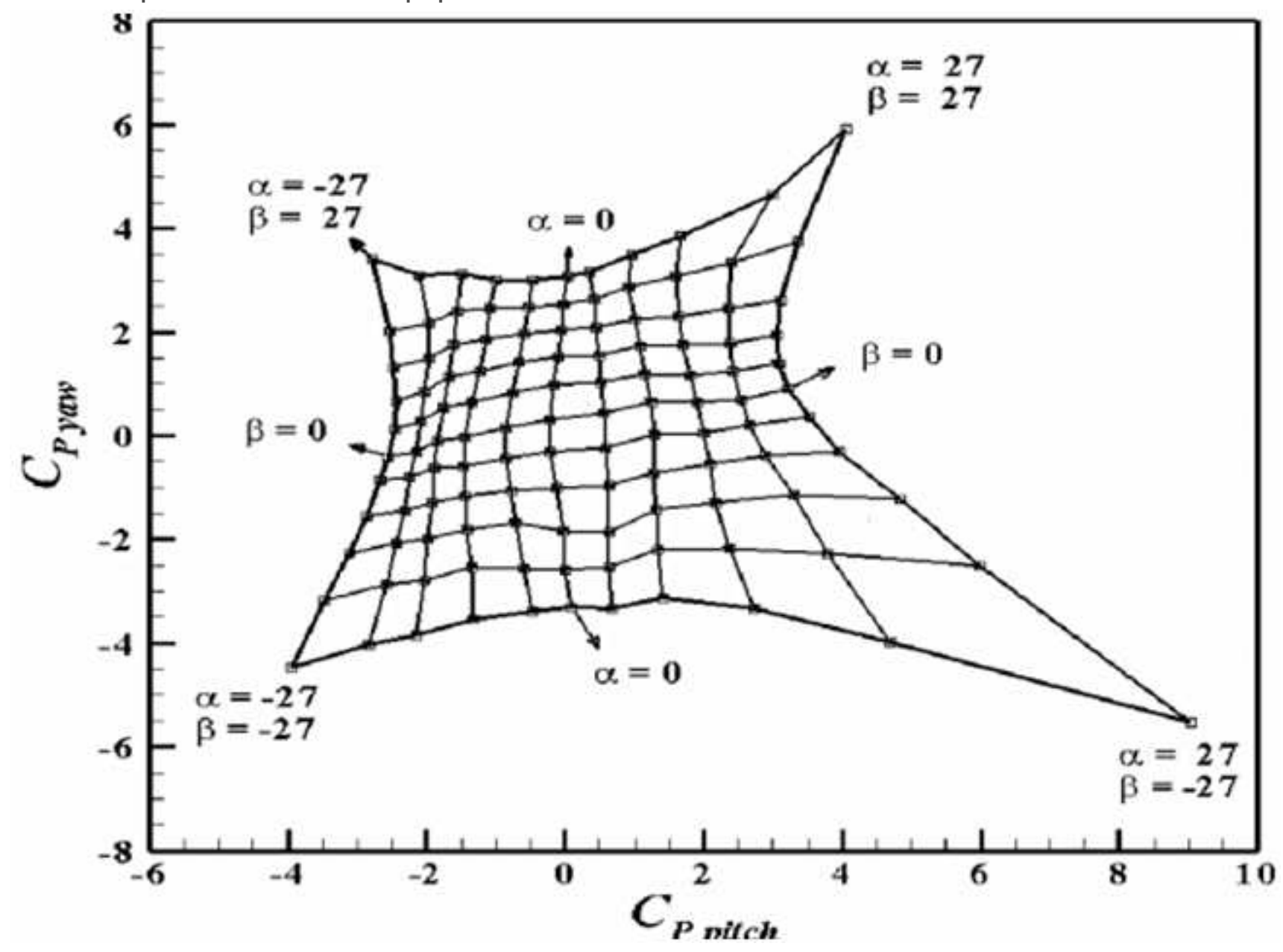

Figure 5

Calibration diagram obtained from five-hole probe calibration curve. 


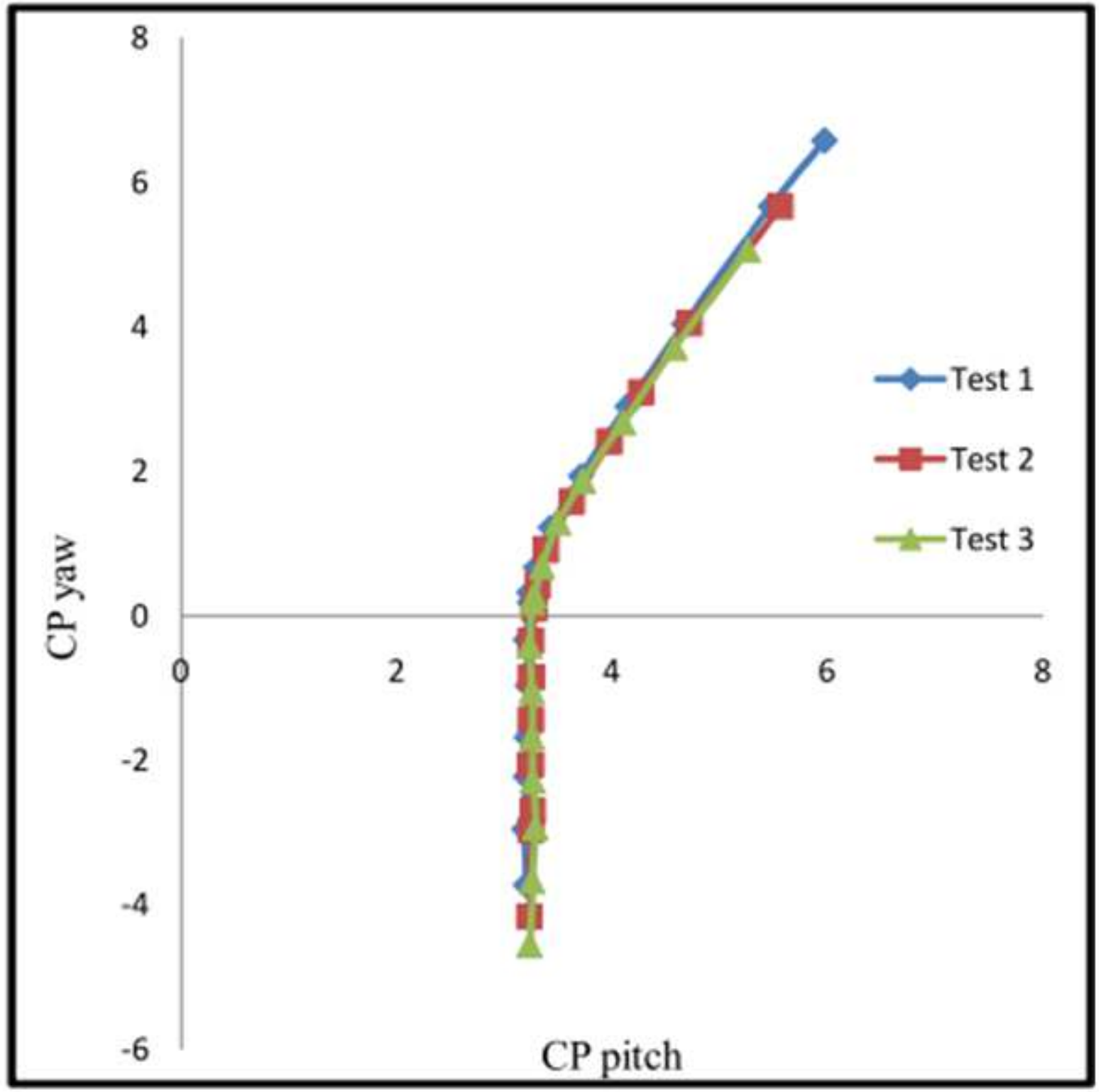

Figure 6

Repeatability test for the calibration curve $(a=21.6)$ for the three tests. 

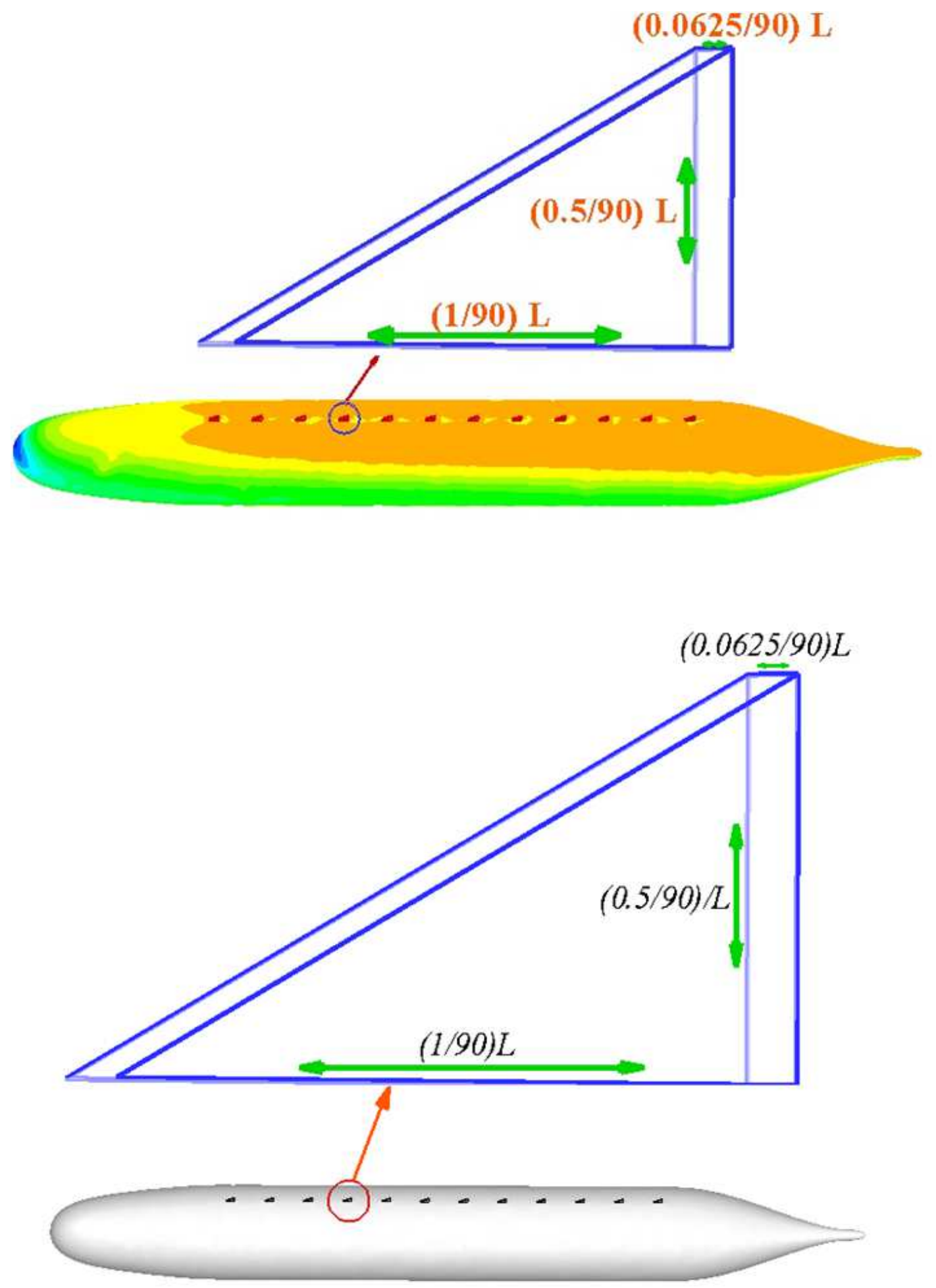

Figure 7

Dimensions and shape of the vane half delta-wing vortex generator. 

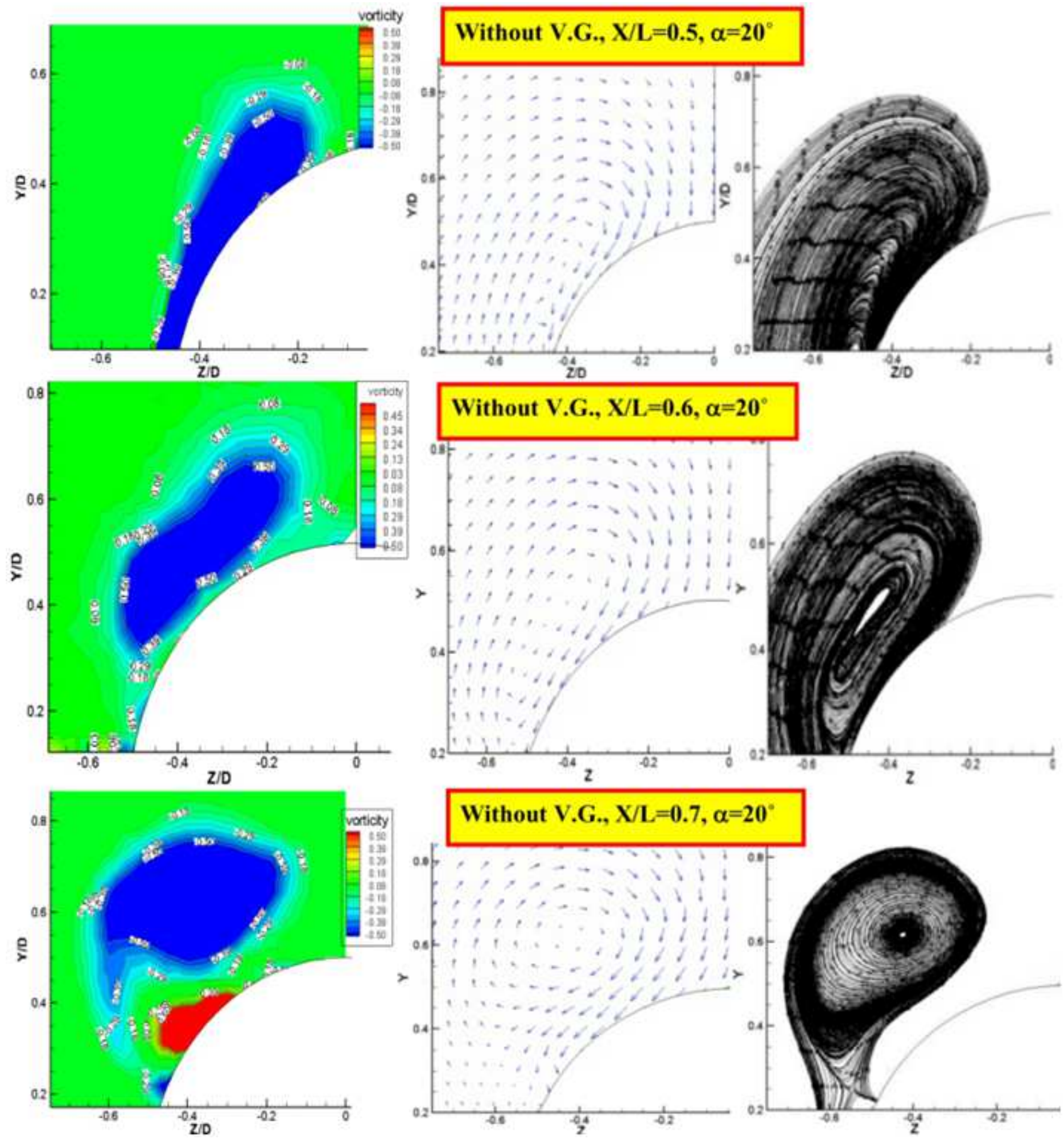

Figure 8

The comparison of vortical flow around bare hull suboff model at different section and at $a=20^{\circ}$ 


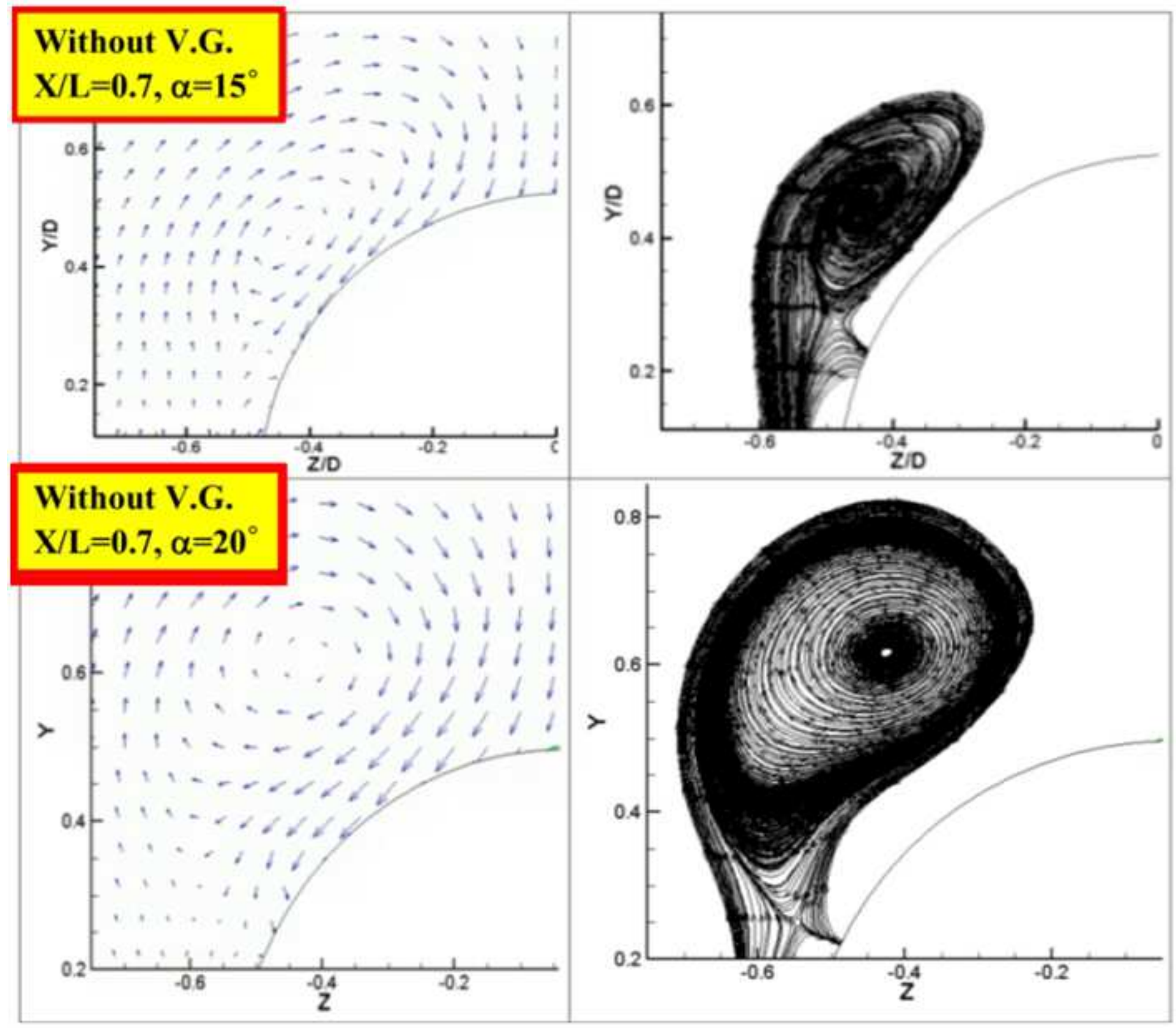

Figure 9

The comparison of velocity contour and vortex flow around the bare hull Suboff model at different angles of attack $\left(a=15 \& 20^{\circ}\right)$ at $X / L=0.7$. 

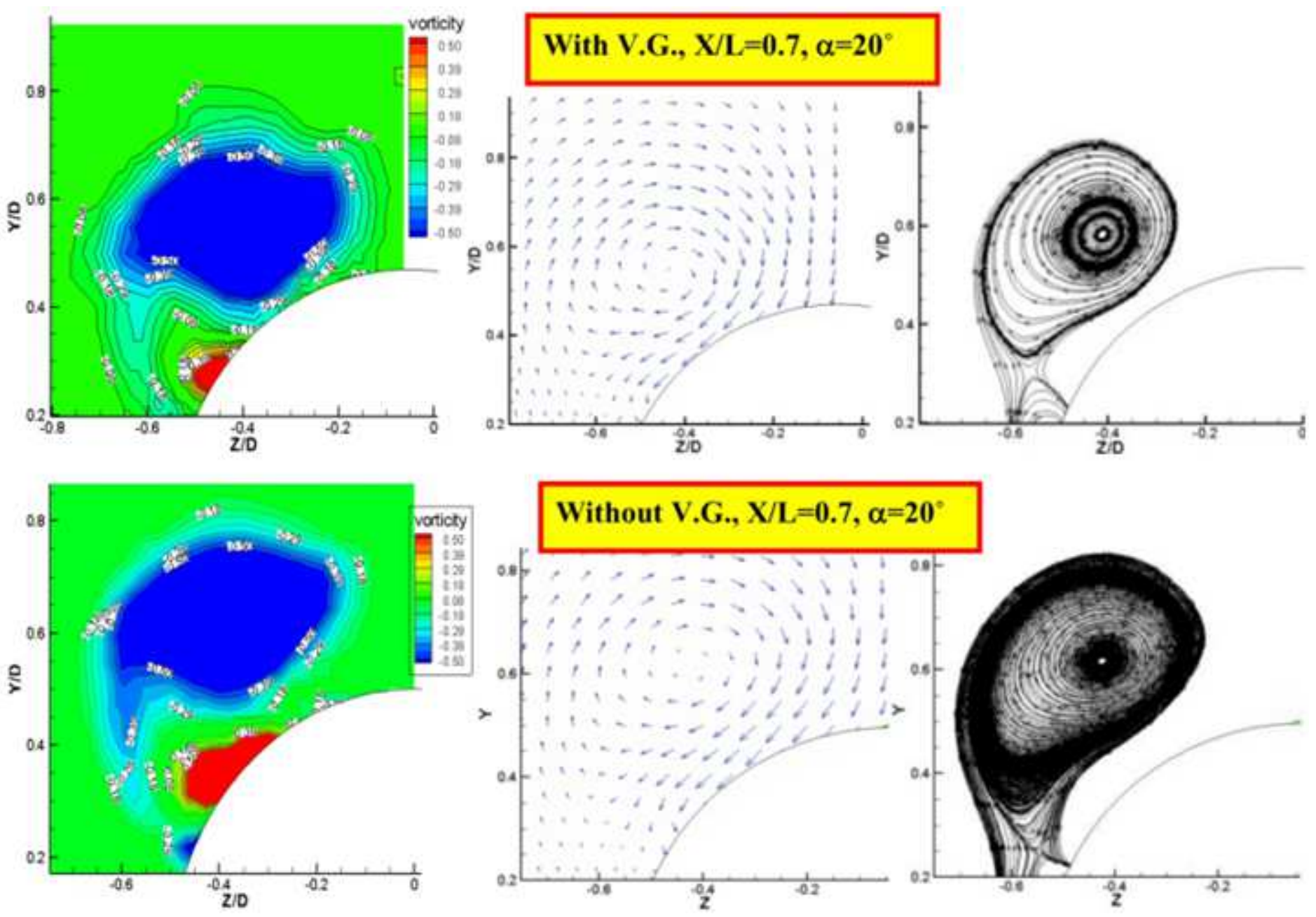

Figure 10

The comparison of vortex flow around the two models (up) with V.G (down) without V.G at $a=20^{\circ}$ and at $\mathrm{X} / \mathrm{L}=0.7$. 


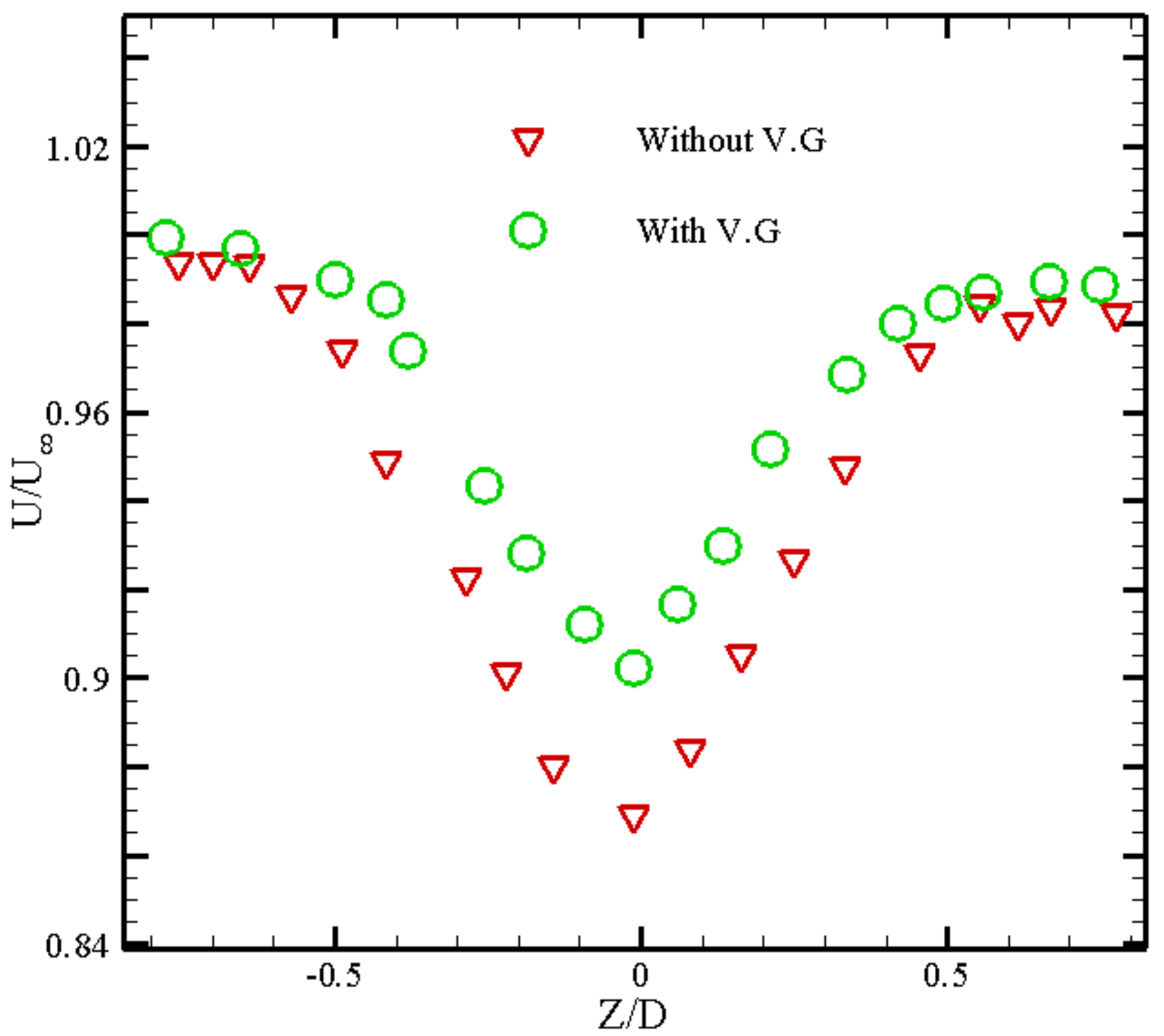

Figure 11

The comparison of reduction speed ration for the models with/without the vortex generators at $X / L=1.1$ 


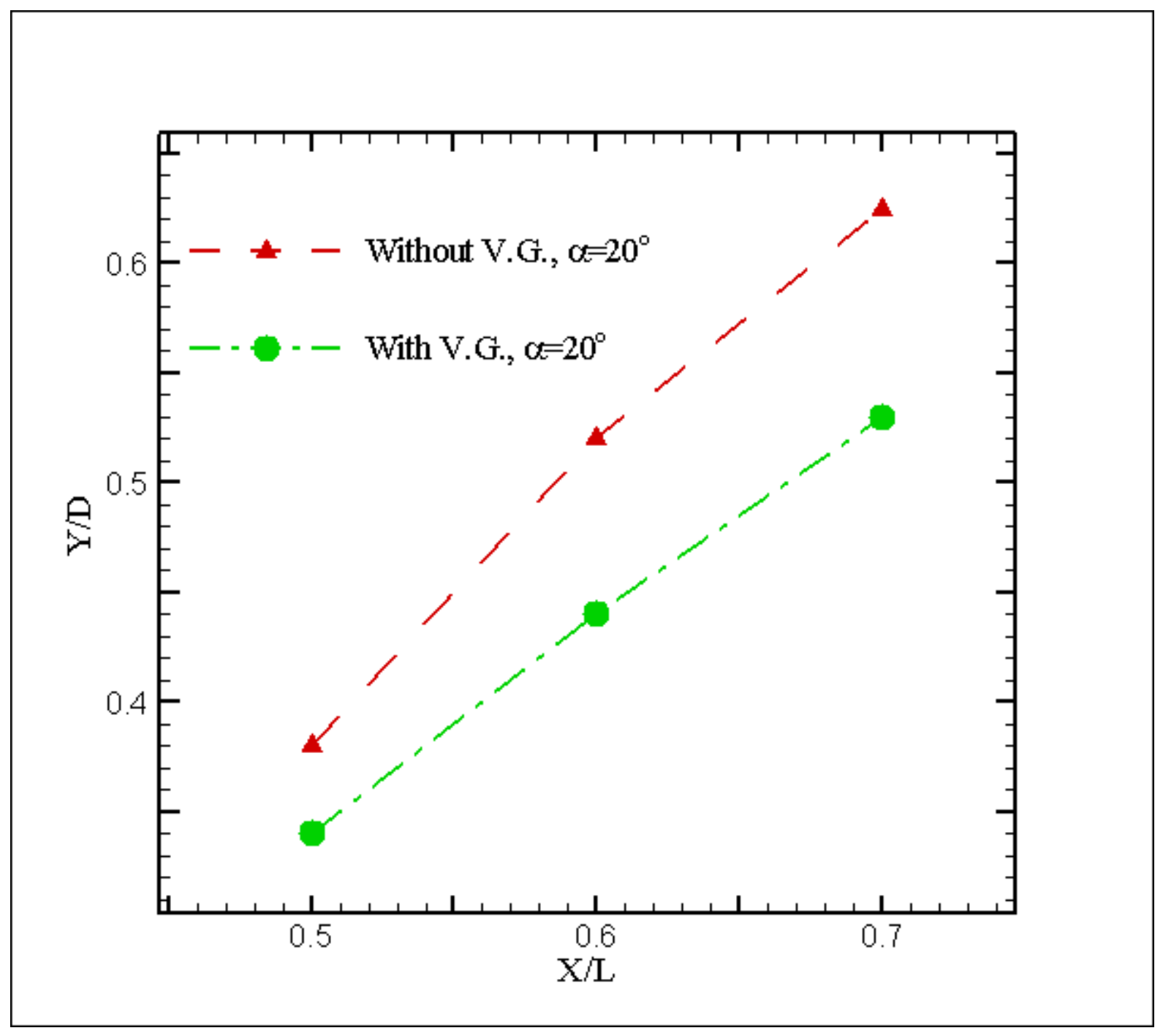

Figure 12

The comparison of amount of vortex core for the models with/without the vortex generators for different section at $\mathrm{a}=20^{\circ}$. 


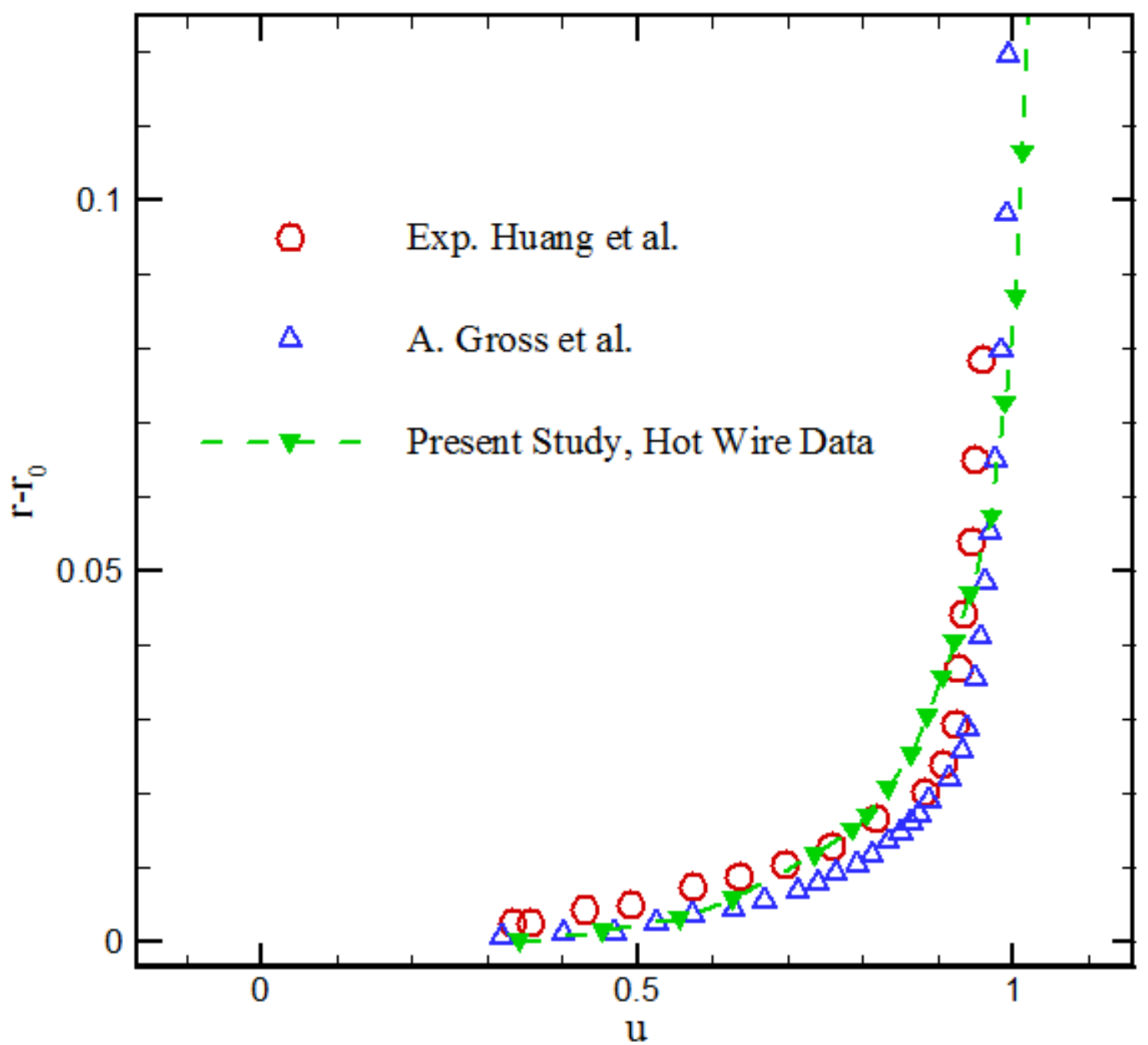

Figure 13

Boundary layer profiles in location $\mathrm{X} / \mathrm{L}=0.9$ at zero pitch angle and $\mathrm{Re}=106$ for SUBOFF model in comparison with experimental study of Huang and Liu. 


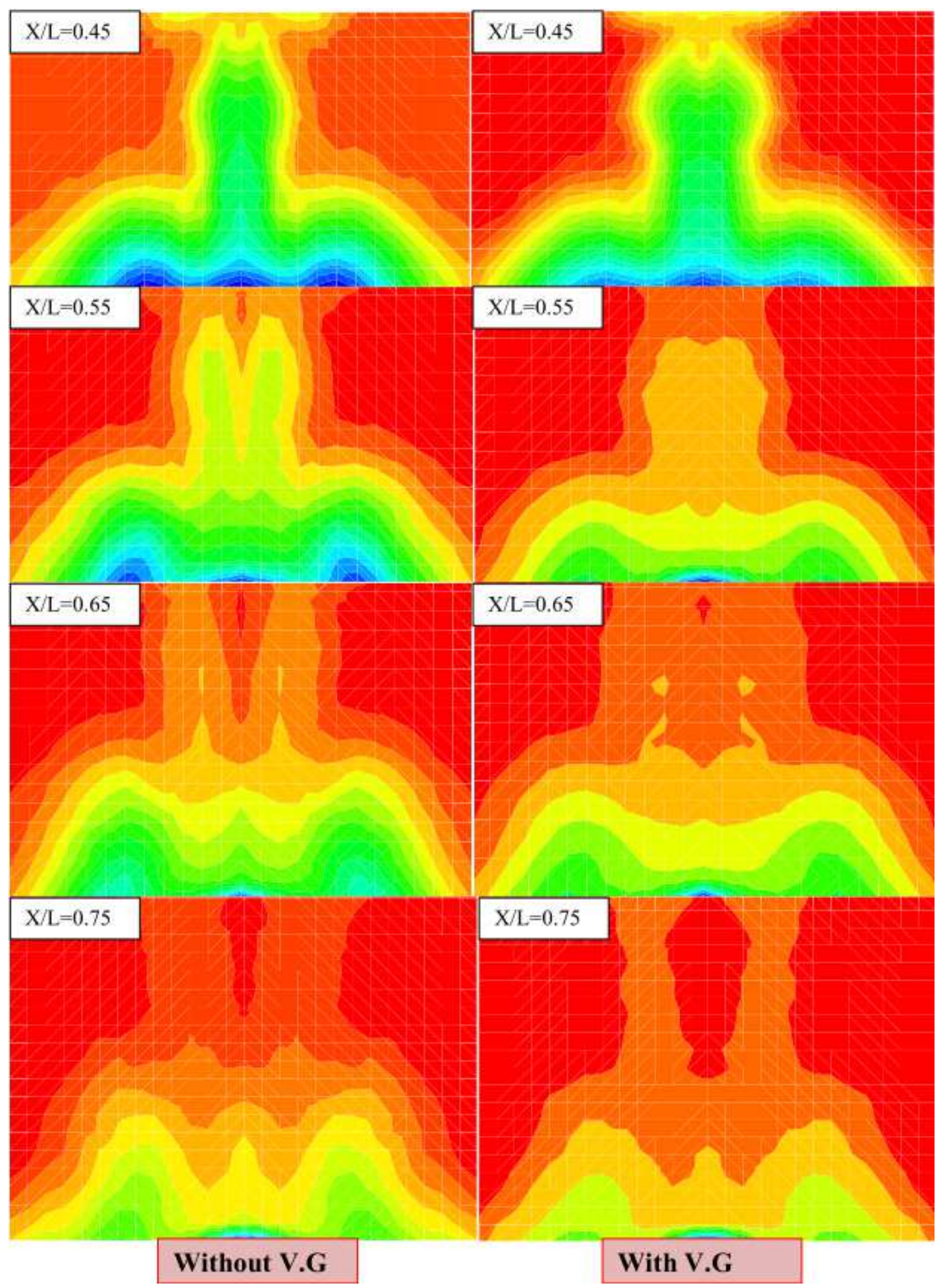

Figure 14

Contours of flow around the Suboff model in four locations $x / L=0.45,0.55,0.65$ and 0.75 along the two body surface (with and without the vortex generators) at angles of attack $10^{\circ}$ and Reynolds number of $1 \times 106$. 


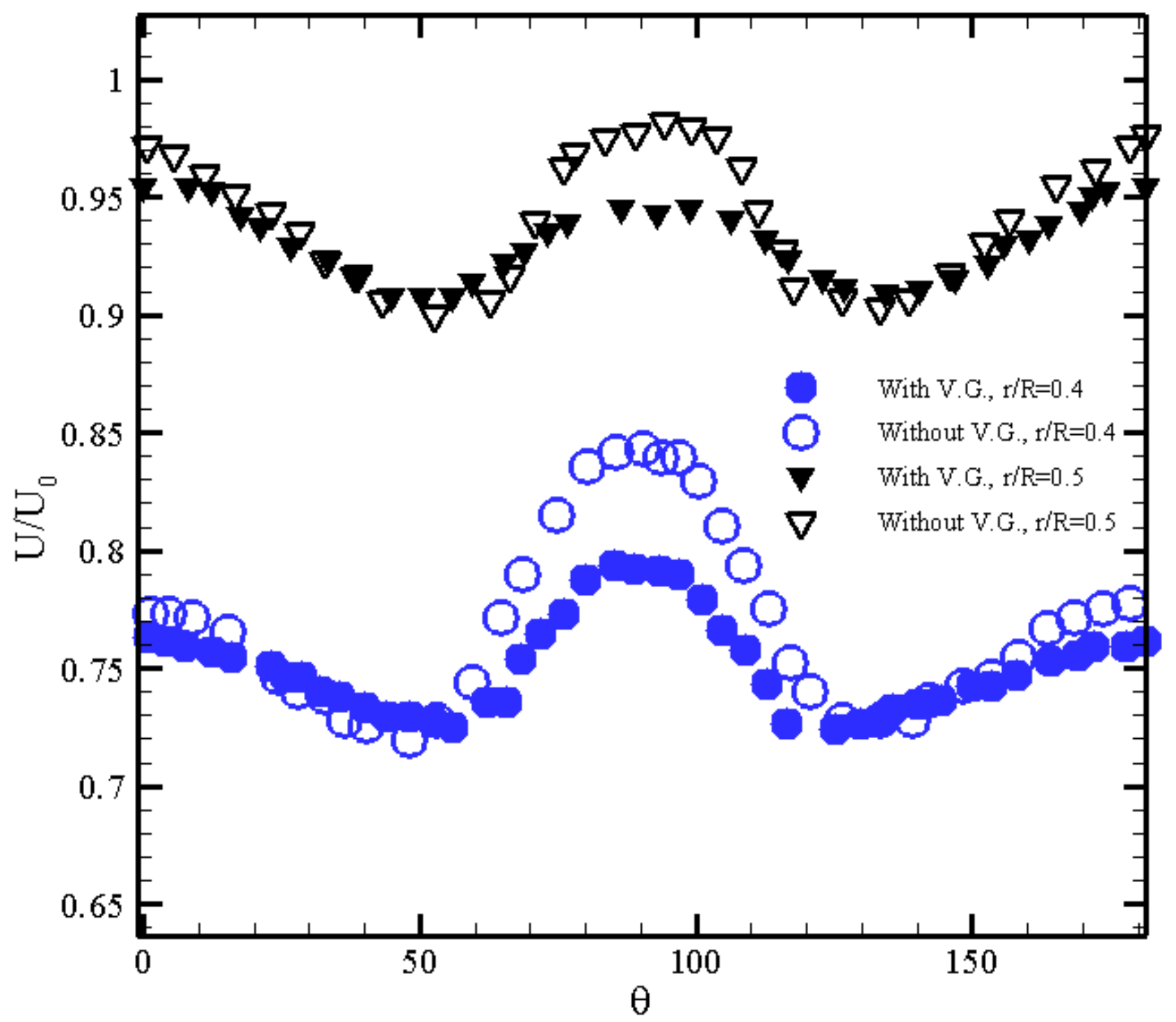

Figure 15

Comparison of axial wake velocity with and without the vortex generators. 


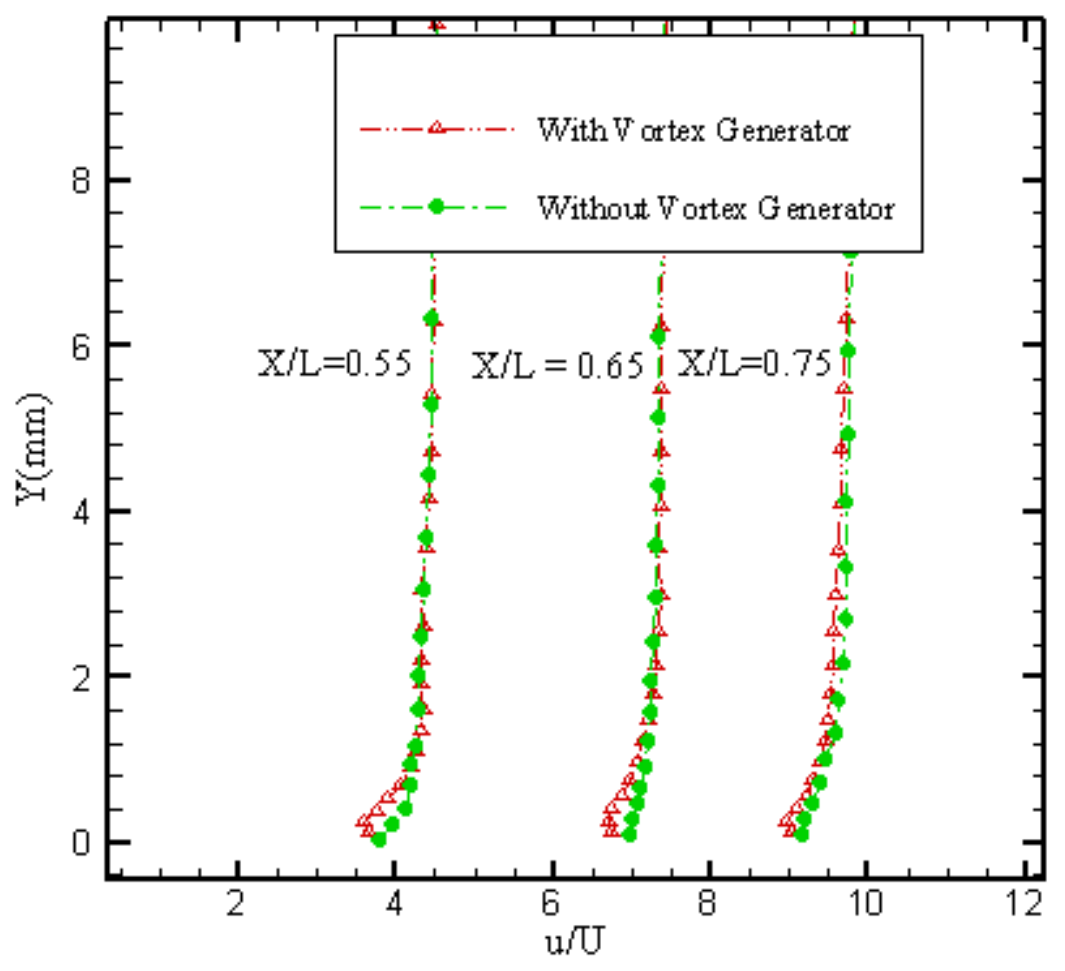

Figure 16

Comparison of Boundary layer profiles in locations $\mathrm{X} / \mathrm{L}=0.55,0.65$ and 0.75 at zero pitch angle and $\mathrm{Re}=$ $1 \times 106$ for the SUBOFF model with/without the vortex generator.
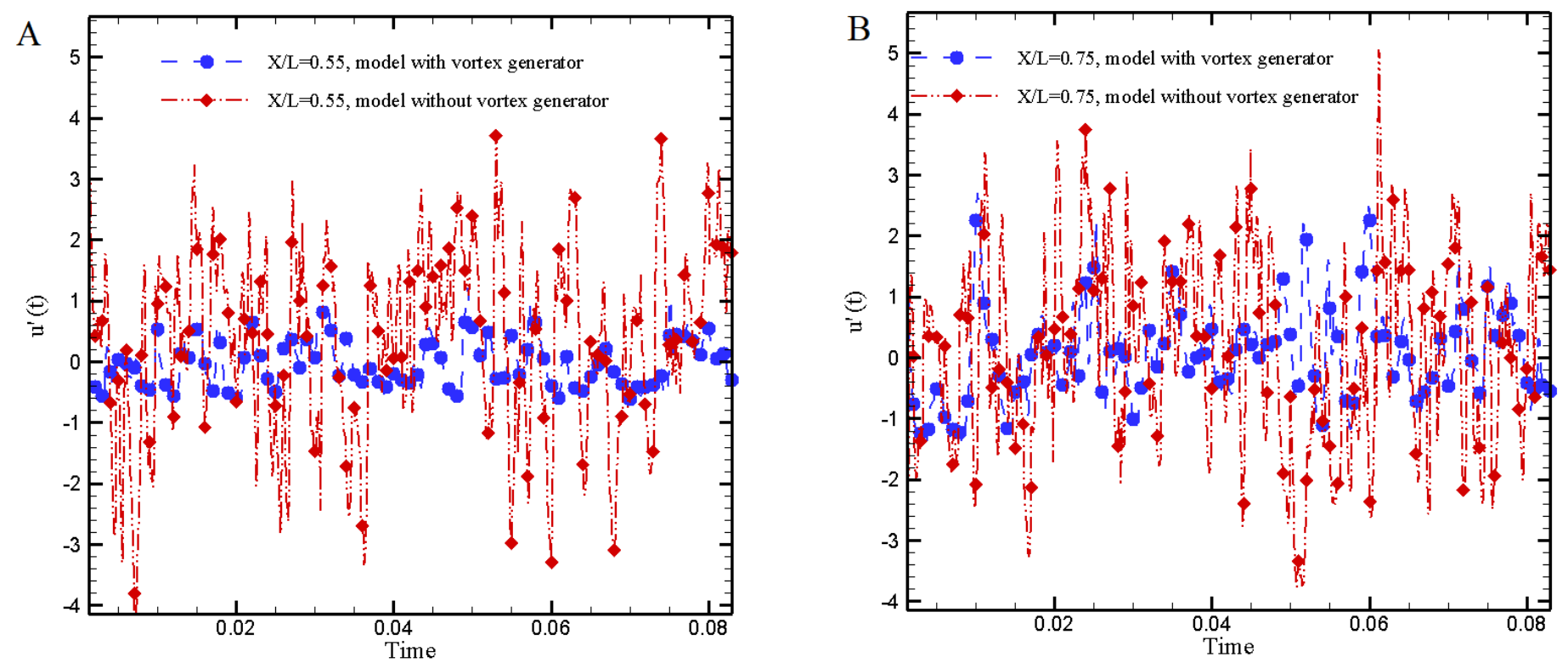

Figure 17

Instantaneous velocity per time at two sections $X / L=0.55$ and 0.75 for two different models. 


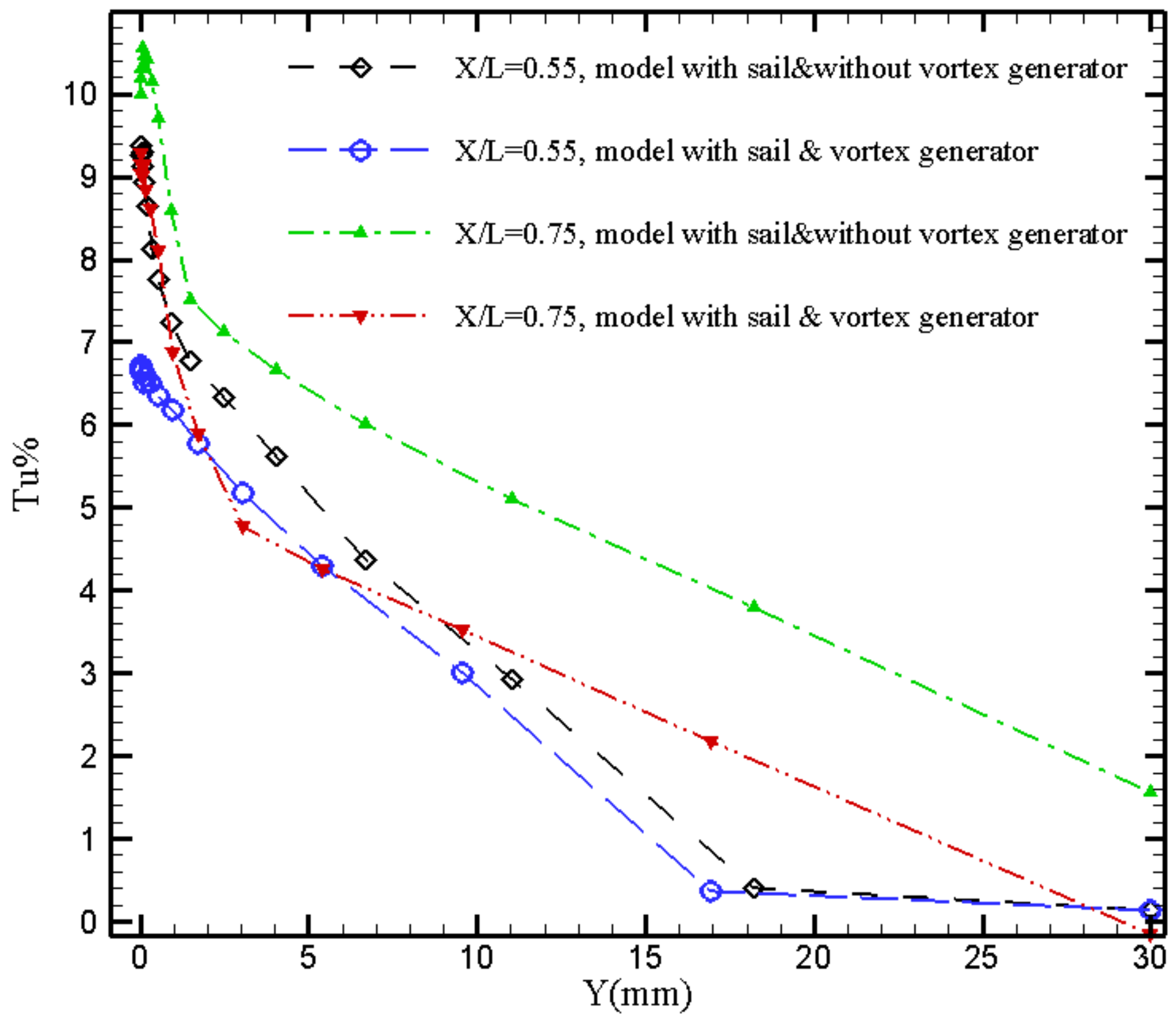

Figure 18

Turbulent intensity at two sections $X / L=0.55$ and 0.75 at $a=10^{\circ}$ and Reynolds number of $1 \times 106$ for two different models. 